\title{
Multilocular Cystic Neoplasm of Low Malignant Potential: A Rare and Incidental Finding of Clear Renal Cell Variant
}

Prachi

Senior resident, Dharamshila Narayana Superspeciality Hospital, New Delhi, India.

*Corresponding Author: Prachi, Senior resident, Dharamshila Narayana Superspeciality Hospital, New Delhi, India.

Received date: June 15, 2021; Accepted date: August 09, 2021; Published date: August 16, 2021

Citation: Prachi. (2021) Multilocular Cystic Neoplasm of Low Malignant Potential: A Rare and Incidental Finding of Clear Renal Cell Variant. International Journal of Clinical Case Reports and Reviews. 8(2); DOI:10.31579/2690-4861/146

Copyright: (C) 2021 Prachi, This is an open-access article distributed under the terms of the Creative Commons Attribution License, which permits unrestricted use, distribution, and reproduction in any medium, provided the original author and source are credited.

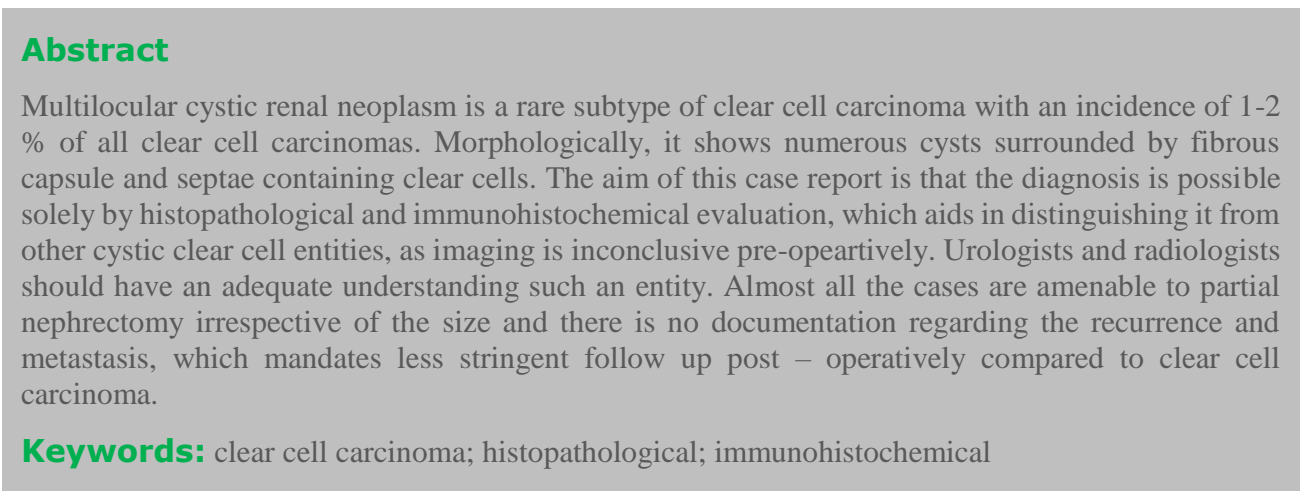

\section{Introduction}

MCRNLMP is a rare subtype of clear cell renal cell tumors and accounts for less than $1 \%$ of renal neoplasms $[1,2]$. Alternative/historical names are multilocular renal cell carcinoma and multilocular cystic renal cell carcinoma. Most of them presents at lower pathological stage (T1 or T2) without invasion into the surrounding perinephric fat or local invasion.

It comprises of numerous cysts and the entity was previously known as multilocular cystic renal cell carcinoma, which usually had clear cell morphology, but was redefined in the 2016 WHO classification due to no recurrence or metastasis in patients with these tumors [3].

The reported incidence is $1-2 \%[4,5]$.

It has variable imaging pattern, the Bosnaik system of classification is used for classifying these renal cysts, ranging from II F to IV, as multilocular cystic lesions increases in complexity on images.

These lesions are strictly defined pathologically, by having thin malignant clear cell lining, and other components such as fibrosis which affects the imaging, hence pre-operative radiological diagnosis is hampered.

Here we present a case in a 58 year old male, who was a diagnosed case of Carcinoma Gall Bladder. On imaging, right renal cyst was suspected, on further histopahological and immunohistochemical evaluation, it was diagnosed as Multilocular cystic clear cell renal cell carcinoma of low malignant potential $(\mathrm{T} 1, \mathrm{Nx})$.

\section{Case History}

A 58 year-old non-smoker male, was a diagnosed case of Carcinoma gall bladder. He did not have any bothersome lower urinary tract symptom or any medical comorbidities. His blood biochemical investigations, renal tests were normal. Liver function tests are mildly deranged due to gall bladder cancer. Ultrasonography of the whole abdomen showed a right upper pole cystic renal mass. Contrast-enhanced computed tomography (CECT KUB) scan showed a well-defined, solitary, partially exophytic mass that was multicystic with solid components within them (Bosniak Category-IV). It was heterogeneously enhancing right upper pole renal mass, measuring $1.4 \times 1.2 \times 0.8 \mathrm{cms}$. The patient underwent radical cholecystectomy for carcinoma gall bladder and laparoscopic partial nephrectomy. Postoperative period was uneventful. Gross examination of the specimen showed a single lesion of size $1.5 \times 1.0 \times 0.8 \mathrm{~cm}$, encapsulated, purely multicystic possessing varying sizes of non-communicating cysts with clear serous or gelatinous material as content. There was no necrosis or solid nodules. Microscopic examination showed a multicystic lesion with thin septal walls of fibro-collagenous connective tissue containing single or occasionally multiple layers of clear cuboidal cells containing abundant cytoplasm .These cells had small hyperchromatic nuclei with regular borders and inconspicuous or absent nucleoli (ISUP grade 1 - low 
grade). Mitotic figures were scarce. No expansile mural nodules, necrosis, vascular invasion, hyalinization or sarcomatoid changes were noted. Immunohistochemistry showed strong membrane positivity for vimentin and epithelial membrane antigen (EMA). Tumour falls under T1bN0M0 with ISUP nuclei grade 1 . The patient is on regular follow-up with imaging studies and is stable. [Figure $1 \mathrm{~A}-\mathrm{D}$ ]

\section{Discussion}

Renal cysts are one of the common findings that we come across during the screening ultrasound abdomen in routine urological practice. Most of them are benign and asymptomatic. They become symptomatic when there is a secondary infection or bleeding within the cysts. The incidence of renal cysts increases with increase in age and seen in over $50 \%$ of patients above 50 years of age.

MCRNLMP represents only 2-4\% of all CCRCC [2]. These tumours develop due to extensive cystic regression or growth within renal tubules, causing obstruction ultimately forming cysts. The term MCRNLMP was first suggested by Suzigan et al [3] in 2006, where they revisited 2004 WHO classification of renal tumours.

The term MCRCC was renamed as MCRNLMP by ISUP in 2013. The WHO Classification of 2016 as well subsequently accepted this change in terminology. MCRNLMP is defined as a multilocular cystic tumour lined by low ISUP grade (1-2) clear cells, immunohistochemically and molecularly not different from CCRCC [6].

Differential diagnoses include cystic nephroma, cystic clear cell papillary RCC and tubulocystic RCC. Cystic nephroma shows the presence of ovarian type stroma. Cystic clear cell papillary RCC also contains clear cells with low-grade nuclei, but differentiating feature is the presence of papillary architecture. Tubulocystic RCC lining cells have eosinophilic cytoplasm with high-grade nuclei instead of clear cells. The differentiating factor for cystic CCRCC is the presence of expansile nodules.

Li et al., [7] concluded that these tumours were predominantly of a low nuclear grade irrespective of tumour size and TNM staging and suggested longer follow-up interval to minimize unnecessary investigations.

Nassir et al. [8] defined MCRNLMP as a predominantly cystic lesion with neoplastic clear cells, probably a subtype of CCRCC having a benign clinical course.

A comparative study between MCRNLMP and predominantly cystic CCRCC by Tretiakova et al. [9] concluded MCRNLMP had uniformly good behavior and support ISUP recommendation for its non-carcinoma designation.

In our case, on post- operative follow up, the patient showed no evidence of recurrence or metastasis. Urologists should have an adequate understanding of this entity because we can adopt longer follow-up intervals for patients with this tumour to minimize unnecessary examinations and patient anxiety.

\section{Conclusion}

It is a rare subtype of CCRCC with low malignant potential and represents $2-4 \%$ of all CCRCC cases. Most cases were detected incidentally and cannot differentiate from other cystic lesions by imaging studies. Histopathology as per WHO guidelines helps in definitive identification. Irrespective of TNM stage, they fall under low risk, and no documented evidence of recurrence or metastasis after complete resection on follow up. Proper understanding of this entity by urologists helps in reducing patient anxiety by adopting longer follow-up intervals and avoiding cumbersome imaging studies.

\section{References}

1. S. Suzigan, A. López-Beltrán, R. Montironi, et al. (2006) Multilocular cystic renal cell carcinoma: a report of 45 cases of a kidney tumor of low malignant potential Am. J. Clin. Pathol. 125; 217-222.

2. W.M. Murphy, D.J. Grignon, E.J. (2004) Perlman AFIP Atlas of Tumor Pathology; 4th series, fascile. Tumors of the Kidney, Bladder, and Related Urinary Structures American Registry of Pathology. Kidney tumors in adults, Washington, DC. 121-123.

3. Suzigan S, Lopez-Beltran A, Montironi R, Drut R, Romero A, Hayashi T, Gentili AL, Fonseca PS, deTorres I, Billis A, Japp LC, Bollito E, Algaba F, Requena-Tapias MJ. (2006) Multilocular cystic renal cell carcinoma: a report of 45 cases of a kidney tumor of low malignant potential. Am J Clin Pathol. 125:217-222.

4. González-Serrano, Adolfo, Cortez-Betancourt, Roberto, AlíasMelgar, Alejandro, Botello-Gómez, Pedro Jair, RamírezGarduño, Emilio, Trujillo-Vázquez, Eric Iván, Torres-Santos, Yosimart, Mata-Martínez, José Antonio, Carreño- de la Rosa, Fernando. (2016) Multilocular Cystic Renal Cell Carcinoma or Cystic Nephroma?. Case Reports in Urology.

5. Li T, Chen J, Jiang Y, Ning X, Peng S, Wang J, He Q, Yang X, Gong K. (2016) Multilocular Cystic Renal Cell Neoplasm of Low Malignant Potential: A Series of 76 Cases. Clinical genitourinary cancer. 14(6):553-557.

6. Montironi R, Lopez-Beltran A, Cheng L, Scarpelli M. (2013) Words of wisdom: re: multilocular cystic renal cell carcinoma with focus on clinical and pathobiological aspects. Eur Urol. 63:400-401.

7. Li T, Chen J, Jiang Y et al. (2016) Multilocular Cystic Renal Cell Neoplasm of Low Malignant Potential: A Series of 76 Cases. Clin Genitourin Canc. 14(6):553-557.

8. Nassir A, Jollimore J, Gupta R, Bell D, Norman R. (2002) Multilocular cystic renal cell carcinoma: a series of 12 cases and review of the literature. Urology. 60: 421-427.

9. Tretiakova M, Mehta V, Kocherginsky M et al. (2018) Predominantly cystic clear cell renal cell carcinoma and multilocular cystic renal neoplasm of low malignant potential form a low-grade spectrum. Virchows Arch. 473: 85-93. 